\title{
Pediatric ventricular assist device use as a bridge to transplantation does not affect long-term quality of life
}

\author{
David S. Ezon, MD, ${ }^{a}$ Muhammad S. Khan, MD, ${ }^{\mathrm{b}}$ Iki Adachi, MD, ${ }^{\mathrm{b}}$ Aamir Jeewa MD, ${ }^{\mathrm{a}}$ \\ Shaine A. Morris, MD, ${ }^{a}$ Celeste Z. Nagy, BS, ${ }^{b}$ David L. S. Morales, MD, ${ }^{b}$ and Jeffrey S. Heinle, MD $^{b}$
}

\begin{abstract}
Objective: The present study sought to determine the long-term quality of life (QOL) of children who required long-term ventricular assist device (VAD) support as a bridge to transplantation (BTT) compared with children who underwent heart transplantation without VAD support. Currently, $20 \%$ of children undergoing heart transplantation have required a VAD as a BTT. Few data have been published assessing how children requiring a VAD as a BTT will fair in terms of their long-term QOL.
\end{abstract}

\begin{abstract}
Methods: The present study used a cross-sectional design, using the Core and Cardiac modules of the Pediatric Quality of Life Inventory survey. In a secondary analysis, the factors associated with worse QOL outcomes among the VAD patients were also investigated.
\end{abstract}

\begin{abstract}
Results: At follow-up (median, 4.2 years), between the 21 children who required a VAD as a BTT and 42 who went straight to transplantation, no significant differences were found in the QOL as measured using the Psychosocial Health Summary Score, Physical Health Summary Score, or Total Score in the survey's Core Module, nor were any differences found in the outcomes assessed using the survey's Cardiac Module. Of the patients who required a VAD, only the presence of a neurologic complication was associated with worse QOL, which was demonstrated by decreased Physical Health Summary and Cardiac Communication scores.
\end{abstract}

Conclusions: Over the long term, surviving children who required a long-term VAD as a BTT experience a similar QOL as those who went straight to transplantation. (J Thorac Cardiovasc Surg 2014;147:1334-43)

In recent years, the number of children supported by a ventricular assist device (VAD) has increased considerably, with up to $20 \%$ of children undergoing heart transplantation requiring a bridge with a $\mathrm{VAD},{ }^{1}$ a dramatic increase from the early 1990 s. $^{2}$ Pediatric VAD use is likely to increase further, given the recent US Food and Drug Administration approval of the Berlin Heart EXCOR Pediatric VAD (Berlin Heart AG, Berlin, Germany). ${ }^{3}$ VADs have been shown to improve survival to transplantation compared with extracorporeal membrane oxygenation (ECMO). ${ }^{4,5}$ VAD use as a bridge to transplantation (BTT) has had equal or better rates of post-transplantation survival compared to medical therapy alone as a BTT, ${ }^{6-13}$ although the outcome data have been limited. With the efficacy of adult and pediatric VAD use established, it is appropriate to assess the long-term outcomes beyond survival alone.

\footnotetext{
From the Section of Pediatric Cardiology a and Section of Congenital Heart Surgery, Texas Children's Hospital, Baylor College of Medicine, Houston, Tex.

Disclosures: Texas Children's Hospital is contracted to be the Berlin Heart Reference and Training Center in the United States. Dr Heinle receives no personal compensation for his involvement with Berlin Heart. All other authors have nothing to disclose with regard to commercial support.

Received for publication July 10, 2013; revisions received Sept 22, 2013; accepted for publication Oct 6, 2013; available ahead of print Dec 16, 2013.

Address for reprints: David S. Ezon, MD, Section of Pediatric Cardiology, Texas Children's Hospital, Baylor College of Medicine, 6621 Fannin St, MC-19345-C, Houston, TX 77030 (E-mail: DSEzon@texaschildrens.org).

0022-5223/\$36.00

Copyright (c) 2014 by The American Association for Thoracic Surgery

http://dx.doi.org/10.1016/j.jtcvs.2013.10.007
}

Pediatric VAD use is associated with a high rate of infection, stroke, and bleeding, ${ }^{4}$ all of which can cause significant morbidity with respect to the neurologic and quality of life (QOL) outcomes. Our aim was to assess the QOL of children who required a long-term VAD as a BTT compared with those patients who went straight to transplantation (STT).

\section{METHODS}

We used a cross-sectional study design to evaluate QOL outcomes in pediatric survivors after heart transplantation, comparing those patients supported with a VAD as a BTT and patients never supported by a VAD.

The patients selected for inclusion had undergone heart transplantation from January 2005 to August 2011 at our institution, were $\leq 18$ years old at transplantation, were $\geq 1$ year post-transplantation, and were alive during the study period. Patients were excluded from the study if they had undergone previous transplantation, had previously been weaned from a VAD, or had undergone multiorgan transplantation. The BTT group was composed of those patients who had required long-term VAD support, defined as $\geq 14$ days. This minimum duration of support was used because it has been our institution's practice to consider long-term use of VADs for patients expected to require support for $\geq 14$ days.

We conducted a secondary analysis limited to those patients supported by a VAD as a BTT to evaluate which patient and device characteristics might be associated with a lower QOL score.

With the approval of our institutional review board, the parents of each patient who had undergone heart transplantation were interviewed by telephone. After obtaining consent, they were asked to complete the Pediatric Quality of Life Inventory (PedsQL) Core Module version 4.0 and the PedsQL Cardiac Module version 3.0 by telephone.

The Core Module of the PedsQL survey consists of 21 to 23 questions that assess the patient's level of physical, emotional, social, and school 


\section{Abbreviations and Acronyms \\ BTT = bridge to transplantation \\ ECMO = extracorporeal membrane oxygenation \\ INTERMACS $=$ Interagency Registry for Mechanically Assisted Circulatory Support \\ PedsQL $\quad=$ Pediatric Quality of Life Inventory \\ QOL $\quad=$ quality of life \\ STT $\quad=$ straight to transplantation \\ TPN $=$ total parenteral nutrition \\ VAD $\quad=$ ventricular assist device}

functioning. The participants are asked to rate the patient's difficulty with various activities or symptoms using a 5-point Likert scale. The score is then translated to a point system from 0 to 100 , where 0 indicates significant impairment in function and 100 indicates no impairment. The scores are then aggregated into a Psychosocial Health Summary Score, consisting of the weighted average of the emotional, social, and school functioning scores, a Physical Health Summary Score, consisting of the physical functioning score, and a total score. The PedsQL includes 5 different surveys according to the patient's age group: 2 to 4,5 to 7,8 to 12,13 to 18 , and 18 to 25 years old. The surveys are similar, with only slight modifications in wording related to patient age (eg, use of the word "teen" instead of "child") and excluding 2 nonapplicable questions for the 2- to 4-year-old group.

The Cardiac Module of the PedsQL survey assesses 6 dimensions of QOL: symptoms related to cardiac disease, problems related to heart medication, problems related to the patient's perceived physical appearance, treatment anxiety, cognitive problems, and communication problems. As with the Core Module, the Cardiac Module has versions for each age group. Because the Cardiac Module does not have a version for patients $>18$ years old, the survey for patients aged 13 to 18 years was used, substituting the term "young adult" for "teen."

The PedsQL survey was administered over the course of 1 month, and the first available parent or guardian was interviewed. The PedsQL Core and Cardiac Modules have been previously validated for both

TABLE 1. Group characteristics

\begin{tabular}{|c|c|c|c|c|}
\hline Characteristic & Total $(n=63)$ & BTT $(\mathbf{n}=21)$ & STT $(n=42)$ & $P$ value \\
\hline \multicolumn{5}{|l|}{ Gender } \\
\hline Male & $36(57)$ & $12(57)$ & $24(57)$ & \multirow[t]{2}{*}{1.00} \\
\hline Female & $27(43)$ & $9(43)$ & $18(43)$ & \\
\hline \multicolumn{5}{|l|}{ Race } \\
\hline Asian & $2(3)$ & $0(0)$ & $2(5)$ & \multirow[t]{4}{*}{.11} \\
\hline Black & $15(24)$ & $7(33)$ & $8(19)$ & \\
\hline Hispanic & $22(35)$ & $10(48)$ & $12(29)$ & \\
\hline White & $24(38)$ & $4(19)$ & $20(48)$ & \\
\hline \multicolumn{5}{|l|}{ Age at follow-up (y) } \\
\hline $2-4$ & $12(19)$ & $7(33)$ & $5(12)$ & \multirow[t]{3}{*}{.54} \\
\hline $5-12$ & $28(44)$ & $5(24)$ & $23(55)$ & \\
\hline$>13$ & $23(37)$ & $9(43)$ & $14(33)$ & \\
\hline \multicolumn{5}{|l|}{ Highest parent reported education } \\
\hline Higher than HS degree & $44(70)$ & $12(57)$ & $32(76)$ & \multirow[t]{3}{*}{.11} \\
\hline HS degree & $11(17)$ & $5(24)$ & $6(14)$ & \\
\hline Less than HS degree & $8(13)$ & $4(19)$ & $4(6)$ & \\
\hline \multicolumn{5}{|l|}{ Heart failure etiology } \\
\hline Acquired & $45(71)$ & $18(86)$ & $27(64)$ & \multirow[t]{2}{*}{.08} \\
\hline Congenital & $18(29)$ & $3(14)$ & $15(36)$ & \\
\hline \multicolumn{5}{|l|}{ Total previous CPB frequency } \\
\hline 0 & $41(65)$ & $17(81)$ & $24(57)$ & \multirow[t]{3}{*}{.03} \\
\hline $1-2$ & $16(25)$ & $4(19)$ & $12(29)$ & \\
\hline$>2$ & $6(10)$ & $0(0)$ & $6(14)$ & \\
\hline Intubated & $20(32)$ & $12(57)$ & $8(19)$ & $<.01$ \\
\hline Hemodialysis use & $2(3)$ & $2(10)$ & $0(0)$ & .11 \\
\hline TPN use & $18(29)$ & $12(57)$ & $6(14)$ & $<.01$ \\
\hline Parent report of current chronic health condition & $12(19)$ & $4(19)$ & $8(19)$ & 1.00 \\
\hline Parent report of overnight hospital visit in previous year & $28(44)$ & $10(48)$ & $18(43)$ & .72 \\
\hline Parent report of ED/urgent care visit in previous year & $32(51)$ & $12(57)$ & $20(48)$ & .48 \\
\hline Age at follow-up (y) & $9.04(5.6-17.3)$ & $7.38(4.3,18.0)$ & $9.42(6.6-15.5)$ & .37 \\
\hline Age at transplantation $(\mathrm{y})$ & $5.13(1.1-12.6)$ & $4.28(1.0-13.5)$ & $5.3(1.22-10.3)$ & .76 \\
\hline Interval since transplantation $(\mathrm{y})$ & $4.21(2.9-5.8)$ & $3.33(2.8-3.8)$ & $4.81(3.4-6.4)$ & $<.01$ \\
\hline Ischemic time* $(\mathrm{min})$ & $263(206-313)$ & $264(211-297)$ & $260(205-327)$ & .96 \\
\hline Poverty level by census block & $12.8(5.3-22.4)$ & $12.8(6.1-29.7)$ & $12.8(4.7-21.6)$ & .44 \\
\hline
\end{tabular}

Data presented as n (\%) or median (interquartile range [25th-75th]). BTT, Bridge to transplantation; $S T T$, straight to transplantation; $H S$, high school; $C P B$, cardiopulmonary bypass; $T P N$, total parenteral nutrition; $E D$, emergency department. *Ischemic time available for only 55 patients. 
TABLE 2. PedsQL Cardiac and Core Module scores

\begin{tabular}{|c|c|c|c|c|c|c|c|}
\hline \multirow[b]{2}{*}{ PedsQL Section } & \multicolumn{2}{|c|}{ Total } & \multicolumn{2}{|c|}{ BTT } & \multicolumn{2}{|c|}{ STT } & \multirow[b]{2}{*}{$P$ value } \\
\hline & Median & IQR & Median & IQR & Median & IQR & \\
\hline \multicolumn{8}{|l|}{ Core Module } \\
\hline Psychosocial Health Summary & 83.3 & $69.2-90.8$ & 81.7 & $70.0-90.0$ & 84.2 & $68.3-91.7$ & .66 \\
\hline Physical Health Summary & 87.5 & 71.9-100 & 90.6 & $75.0-96.9$ & 84.4 & $68.8-100$ & .80 \\
\hline Total score & 82.6 & $71.0-91.3$ & 81.94 & $70.7-92.9$ & 82.6 & $71.7-91.3$ & .53 \\
\hline \multicolumn{8}{|l|}{ Cardiac Module } \\
\hline Heart problems and treatment & 89.3 & $85.4-96.4$ & 92.9 & $85.7-100$ & 89.3 & $82.1-96.4$ & .28 \\
\hline Treatment II & 100 & $90.0-100$ & 95.8 & $83.0-100$ & 100 & $90-100$ & .33 \\
\hline Perceived physical appearance & 100 & $83.3-100$ & 100 & $83.3-100$ & 100 & $83.3-100$ & .54 \\
\hline Treatment anxiety & 100 & $75.0-100$ & 87.5 & $62.5-100$ & 100 & $81.3-100$ & .43 \\
\hline Cognitive problems & 80.0 & $50.0-95$ & 80 & $50.0-95.0$ & 77.5 & $55.0-95.0$ & .58 \\
\hline Communication & 100 & $75.0-100$ & 100 & $66.7-100$ & 100 & $83.3-100$ & .28 \\
\hline
\end{tabular}

PedsQL, Pediatric Quality of Life Inventory; BTT, bridge to transplantation; STT, straight to transplantation; IQR, interquartile range (25th-75th percentiles).

in-person and telephone acquisition. ${ }^{14-17}$ Each survey was administered by 1 of 2 trained instructors, who followed the PedsQL script exactly and audited each other's interviews to ensure consistency was maintained. For Spanish-speaking parents, an interviewer fluent in Spanish conducted the interview.

Although the PedsQL survey includes both a parent survey and a self-survey completed by the patient, the present study used only the parent survey to ensure interview feasibility by telephone and to maintain consistency among the patients of each age group. The parent survey has been validated independently of the self-survey. ${ }^{16}$

The potential confounders of the relationship between pretransplantation VAD support and QOL were considered a priori and were collected from the electronic medical record systems and available billing data. Data were collected for each patient's demographic information, age at transplantation, age at the PedsQL survey, heart failure etiology, medical history, time since transplantation, and current health condition as perceived by the parents, including recent illnesses, hospital admissions, or presentation to the emergency room.

As a proxy for socioeconomic status, the percentage of persons living in poverty in the patient's census block group, a previously validated measure, was collected from the 2010 United States Census data. ${ }^{18,19}$ For 3 patients,

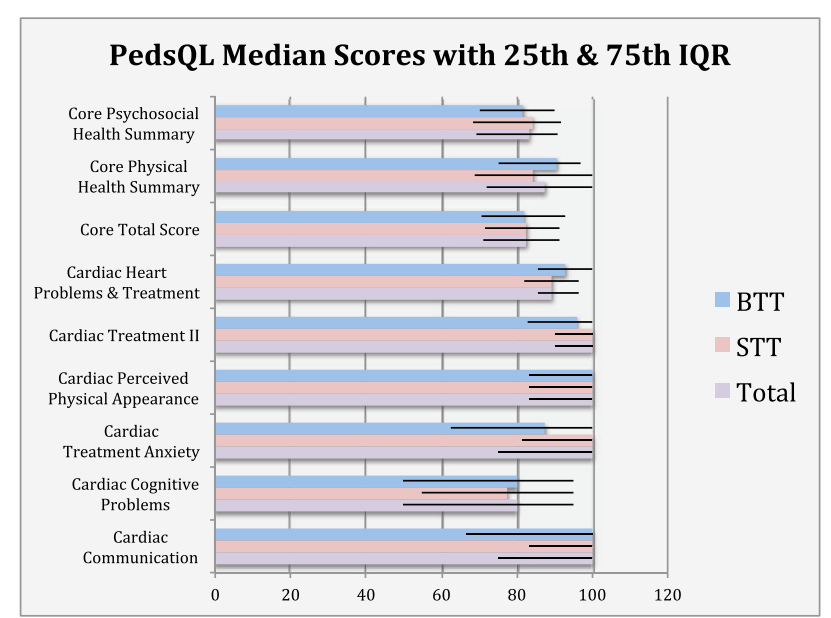

FIGURE 1. Median Pediatric Quality of Life Inventory scores and 25th to 75th interquartile range $(I Q R)$. The scores were similar for the bridge to transplantation (BTT) and straight to transplantation (STT) groups in each of the core and cardiac categories. the residential address was unknown, so the poverty level for the ZIP code of the patient's post office box was used.

For the secondary analysis evaluating the variables associated with lower PedsQL scores within the VAD group, the Interagency Registry for Mechanically Assisted Circulatory Support (INTERMACS) score at VAD implantation, VAD duration, VAD type, and VAD complications were collected. The data collected to assess whether a patient required mechanical ventilation, hemodialysis, or total parenteral nutrition (TPN) at VAD implantation were taken from billing data for the day before VAD implantation because applicable medical records were not available for all patients. For comparison, similar data were collected for STT patients from the day before transplantation. A patient was considered to have had a neurologic complication if either a new neuroradiologic finding appeared while the patient was maintained on the VAD or new neurologic symptoms developed during VAD support (eg, seizure).

Descriptive data were reported using proportions, medians, and 25th to 75 th percentile interquartile range. A comparison of the characteristics between the BTT and STT groups was performed using the $\chi^{2}, \chi^{2}$ for trend, and Fisher exact tests for categorical variables and the Mann-Whitney $U$ or Kruskal-Wallis test for continuous variables, as appropriate. A comparison of the QOL scores between the BTT and STT groups and among the characteristics within the VAD subanalysis were performed using the Mann-Whitney $U$ test and Spearman's rank correlation. The 5- to 7-yearold group was combined with the 8- to 12-year-old group for the individual analysis by age group, because the latter group contained only 1 BTT patient.

\section{RESULTS}

From January 2005 to August 2011, 101 patients underwent heart transplantation at Texas Children's Hospital. Of these, 34 required a VAD before transplantation. Of the 101 patients, 26 were excluded from the study ( 8 BTT and 18 STT patients) because they did not meet the inclusion criteria, and 12 (5 BTT and 7 STT patients) were excluded because they were deceased at the time of the study. The remaining 63 patients (21 BTT and 42 STT) were included in the study. The parents or guardians of all included patients were successfully contacted. One parent, whose child was in the STT group, declined to complete the survey, yielding a $98 \%$ completion rate. Of the surveyed BTT patients, 13 had been supported with a Berlin EXCOR (Berlin Heart AG), 6 with a HeartMate II 
(Thoratec Corp, Pleasanton, Calif), 1 with a Rotaflow (Maquet Cardiovascular, Wayne, NJ), and 1 with a Micromed VAD (MicroMed Technology, Inc, Houston, Tex). The median duration of VAD support was 80 days (range, 16-262).

Four patients surveyed were supported by ECMO at 1 point in their course, 2 of whom were bridged to transplantation with a VAD. Only 1 patient required ECMO for $>5$ days, and he was not in the VAD group.

The median age at transplantation was 5.1 years (range, 2 months to 18 years), and the median age at follow-up was 9 years, with no significant differences in age between the BTT and STT groups (Table 1). The BTT patients had undergone heart transplantation more recently, with a median interval since transplantation of 3.3 years (interquartile range, 2.7-3.8) versus 4.8 years (interquartile range, 3.4-6.4, $P<.01$ ) for the STT patients. The 2 groups had similar characteristics of gender, race, socioeconomic status, and parent education. The BTT patients were more likely to have been supported with TPN and ventilator support on the day before VAD placement. No significant difference was found in the incidence of recent illness, presentation to the hospital, or perceived chronic health condition, as reported by the parents, factors that might have influenced the parental response to the survey.

The median Psychosocial Health Summary Score, Physical Health Summary Score, and total score for the PedsQL Core Module were similar for the BTT and STT groups (Table 2 and Figure 1). The median total score for the Core Module was 82.6, similar to that of healthy subjects, previously demonstrated to have a mean total score of 82.3. ${ }^{17}$ The median scores of the BTT and STT patients were also similar to the mean scores for patients with moderate cardiovascular disease, defined as those patients who had undergone surgically correction or no longer required therapy, who were previously shown to have a mean total score of 84.6. ${ }^{20}$ Median data from either study were unavailable for comparison. The scores were also compared by each age-stratified subgroup for the 6 dimensions of the PedsQL Cardiac Module. No difference was found in the outcomes for BTT patients compared with the STT patients (Appendix Table 1).

The secondary analysis of scores for patients who required a VAD as a BTT for any VAD specific factors that might have affected the QOL outcome demonstrated significant findings (Appendix Table 2). The QOL scores did not differ by VAD duration, age at transplantation, or INTERMACS score at VAD placement (Table 3). Of the VAD patients, $62 \%$ were supported by a pulsatile VAD, and the scores were not different between those with pulsatile versus continuous VAD support. Additional indicators of the patient's degree of illness at VAD placement, including ventilatory support, hemodialysis use, and TPN use, were not associated with a significant difference in outcome. Also, the patients faired similarly regardless of whether the etiology of heart failure was acquired or congenital heart disease and regardless of the number of previous cardiopulmonary bypass runs they had experienced. No differences were found in the QOL scores among the race categories or by socioeconomic status. Complications, including VAD-related infection, reoperation or pump change, and neurologic complications, were also assessed. Only the presence of a neurologic complication $(\mathrm{n}=5)$ was associated with a lower QOL score, with a statistically significant difference in the patient's Physical Health Summary score (50 vs 94) and Cardiac Communication score (67 vs 100).

In the BTT patients, the interval since transplantation had a moderate positive correlation with the QOL score in the Cardiac Communication dimension that was statistically significant (correlation coefficient, $0.52 ; P=.01$ ). Patient age at follow-up also demonstrated a moderate positive correlation with the Cardiac Communication score in the BTT patients.

\section{DISCUSSION}

Recent evidence has shown that a VAD can effectively support a pediatric patient to heart transplantation. ${ }^{21}$ However, pediatric VAD support has had a significant complication rate, especially for younger children requiring extracorporeal devices, with the potential to affect the long-term QOL of patients. These complications have included bleeding (42\%-50\%), infection (50\%-63\%), and stroke $(29 \%) .{ }^{4}$ The present study is the largest to date to assess the long-term QOL outcomes of pediatric patients who required VAD support as a BTT compared with patients who went STT.

One recent study used the PedsQL Core Module to determine the QOL outcomes in patients using mechanical circulatory support. However, these had focused mainly on patients bridged with ECMO, with, at most, 11 patients sustained by a VAD. The study found similar QOL outcomes for patients requiring mechanical circulatory support compared to the STT group. ${ }^{22}$

In a recent study by Uzark and colleagues ${ }^{23}$ of the long-term QOL outcomes of 174 pediatric patients who had undergone heart transplantation, the patients demonstrated significantly lower psychosocial and physical functioning scores compared with the healthy norms and patients who had undergone curative heart surgery. VAD use was not evaluated in their study. ${ }^{23}$

Our study did not demonstrate any statistically significant difference between the BTT and STT patients for the Core or Cardiac Module outcomes, either in total or for each age category. Both groups also scored similarly to published normative values for the PedsQL survey. More than 33\% of heart transplantation patients in the study by Uzark and colleagues ${ }^{23}$ had impaired psychosocial functioning scores, 
TABLE 3. Factors affecting outcome of patients bridged to transplantation with VAD

\begin{tabular}{|c|c|c|c|c|c|c|c|}
\hline \multirow[b]{2}{*}{ PedsQL section } & \multicolumn{3}{|c|}{ Neurologic complication } & \multicolumn{3}{|c|}{ VAD type } & \multirow{2}{*}{$\begin{array}{c}\text { Gender } \\
\text { Male }(n=12)\end{array}$} \\
\hline & Yes $(n=5)$ & No $(n=16)$ & $P$ value & Pulsatile $(n=13)$ & Continuous $(n=8)$ & $P$ value & \\
\hline \multicolumn{8}{|l|}{ Core } \\
\hline Psychosocial & $61.7(61.5-84.6)$ & $82.5(71.7-90.8)$ & .24 & $84.6(65.4-92.3)$ & $76.7(70-83.3)$ & .34 & $74.17(62.6-86.7)$ \\
\hline Physical & $50(34.4-78.1)$ & $93.8(76.6-100)$ & .01 & $90.6(62.5-100)$ & $89.1(76.6-95.3)$ & .86 & $92.18(68.7-100)$ \\
\hline Total & $68.1(51.2-71.2)$ & $85.32(79.4-93.2)$ & .09 & $85.9(67.9-93.5)$ & $80.4(74.5-85.3)$ & .64 & $82.61(66.1-89.7)$ \\
\hline \multicolumn{8}{|l|}{ Cardiac } \\
\hline $\begin{array}{l}\text { Heart problems and } \\
\text { treatment }\end{array}$ & $92.86(78.6-92.9)$ & $91.1(85.7-100)$ & .49 & $92.9(89.3-100)$ & $85.7(82.1-96.4)$ & .30 & $98.21(87.5-100)$ \\
\hline Treatment II & $91.7(90.0-100)$ & $100(80.0-100)$ & .90 & $100(83.3-100)$ & $90(80-100)$ & .41 & $95.83(81.7-100)$ \\
\hline $\begin{array}{l}\text { Perceived physical } \\
\text { appearance }\end{array}$ & $100(83.3-100)$ & $100(87.5-100)$ & .90 & $100(91.7-100)$ & $100(62.5-100)$ & .59 & $100(91.7-100)$ \\
\hline Treatment anxiety & $100(75.0-100)$ & $87.5(59.4-100)$ & .72 & $87.5(62.5-100)$ & $100(68.8-100)$ & .37 & $100(71.9-100)$ \\
\hline Cognitive problems & $50(30.0-91.7)$ & $80(50-97.5)$ & .40 & $50(50-83.3)$ & $90(62.5-100)$ & .21 & $55(42.5-92.5)$ \\
\hline Communication & $66.67(0-83.3)$ & $100(83.3-100)$ & .02 & $83.3(25.0-100)$ & $100(95.8-100)$ & .14 & $100(66.7-100)$ \\
\hline
\end{tabular}

Data presented as median (IQR [25th-75th percentile]) or correlation coefficient. VAD, Ventricular assist device; PedsQL, Pediatric Quality of Life Inventory; INTERMACS, Interagency Registry for Mechanically Assisted Circulatory Support.

defined as a score $>1$ standard deviation below the population mean. Our patients faired much better, with only $14 \%$ of STT patients and $19 \%$ of BTT patients scoring low.

Our outcomes are more consistent with the results of another study by Uzark and colleagues ${ }^{20}$ which demonstrated that nearly $16 \%$ of patients with cardiovascular disease of any sort had impaired psychosocial functioning scores. The scores were inversely proportional to the degree of cardiovascular illness. The patients in our study had a median total score similar to the mean total score of the children in the study by Uzark and colleagues ${ }^{20}$ who had had moderate cardiovascular disease, defined as those who had undergone curative surgery or no longer required medications.

We found few statistically significant risk factors among the patients who required a VAD. Neurologic complications, including radiologically evident stroke and seizures, were associated with poorer Physical Health Summary scores on the Core Module and lower Communication scores on the Cardiac Module. This might reflect the long-term nature of the neurologic injury sustained by the patient and should raise concerns about the patient's future neurodevelopment. Closer long-term follow-up might be indicated for these patients to assess and treat any developmental problems that occur.

Although the recent Berlin Heart study by Fraser and colleagues ${ }^{4}$ reported that the complication rate increased with VAD duration, the present study did not establish any significant correlation between VAD duration and QOL outcome. The difference might have been because the study by Fraser and colleagues ${ }^{4}$ considered all patients with VAD use, including nonsurvivors, and our study the assessed outcomes only for patients well enough to both survive to transplantation and be alive at the time of the present study.
Although the severity of illness at transplantation has been shown to increase the risk of graft rejection in the long term in pediatric patients, ${ }^{24}$ the INTERMACS score, need for ventilatory support, TPN, or hemodialysis at VAD placement did not correlate with the QOL outcome. Also, the heart failure etiology did not affect the outcome. It might be that maintenance of adequate cardiac output with a VAD while awaiting transplantation is associated with improved post-transplantation QOL in patients who are particularly ill, or it might be a reflection of selection bias.

Among the BTT patients, both age at follow-up and the interval since transplantation had a moderate positive correlation with the Cardiac Communication score. The questions constituting the PedsQL Cardiac Communication assessment have focused on the patients' ability to discuss their medical condition with others, an ability that likely increases with age, explaining why a longer interval since transplantation demonstrated improved outcomes.

Altogether, our results have shown that patients who require a VAD to maintain circulatory support as a BTT are likely to have QOL outcomes, as perceived by their parents, comparable to those who went STT. Furthermore, the indicators of the child's degree of illness at VAD implantation, measures of the child's socioeconomic status, and VAD type does not appear to affect the QOL outcomes. Only the occurrence of neurologic complications was shown to have some potential effect on the long-term outcomes.

One limitation of the present study was its small sample size, which might have limited the power to detect more subtle differences between the 2 groups. Another limitation was the use of only the parent survey. This was done both to maximize the response rate, given the easier access to patients by telephone, and to have comparable results across all age groups. Previous studies have shown the correlation 
TABLE 3. Continued

\begin{tabular}{|c|c|c|c|c|c|c|c|}
\hline \multicolumn{2}{|l|}{ Gender } & \multicolumn{2}{|l|}{ VAD duration } & \multicolumn{2}{|c|}{ Age at transplantation } & \multicolumn{2}{|c|}{ INTERMACS score at VAD placement } \\
\hline Female $(\mathbf{n}=\mathbf{9})$ & $P$ value & Correlation coefficient & $P$ value & Correlation coefficient & $P$ value & Correlation coefficient & $P$ value \\
\hline $84.62(81.7-92.3)$ & .07 & 0.13 & .56 & -0.11 & .62 & -0.32 & .17 \\
\hline $87.5(75.0-93.7)$ & .60 & -0.07 & .75 & 0.25 & .26 & 0.05 & .83 \\
\hline $81.94(78.3-92.9)$ & .38 & 0.06 & .81 & 0.08 & .71 & -0.25 & .30 \\
\hline $85.71(85.7-92.9)$ & .07 & -0.02 & .93 & -0.06 & .79 & -0.64 & .79 \\
\hline $100(83.3-100)$ & .86 & 0.12 & .59 & 0.02 & .92 & -0.32 & .18 \\
\hline $100(83.33-100)$ & .46 & -0.005 & .98 & -0.06 & .81 & 0.23 & .35 \\
\hline $75(56.25-100)$ & .34 & 0.05 & .82 & 0.41 & .06 & 0.02 & .93 \\
\hline $80(50-95)$ & .46 & 0.185 & .42 & 0.32 & .16 & -0.01 & .97 \\
\hline $100(33.3-100)$ & .86 & -0.351 & .12 & 0.36 & .11 & -0.18 & .46 \\
\hline
\end{tabular}

to be high between the parental and child response, and we believe the inclusion of patient responses would not have resulted in significantly different results. ${ }^{17,22,23}$ Although the results demonstrated similar parental perceived QOL between the BTT and STT groups, only limited conclusions could be drawn about the patient's perceived QOL. Finally, our study was an assessment of the QOL in surviving patients. Thus, the results could reflect survivor bias, because the QOL could not be measured in the most severely ill patients who had died.

\section{CONCLUSIONS}

The results of the present study have helped to establish that the QOL is similar between VAD-supported patients and those who went STT. Additional studies are required to assess the long-term QOL of VAD patients as the technology evolves. Incorporating QOL scores and preventative strategies into patient care may be beneficial. The present study provides additional information to clinicians, patients, and their families during the decision-making process for VAD use.

\section{References}

1. Kirk R, Dipchand AI, Edwards LB, Kucheryavaya AY, Benden C, Christie JD, et al. International Society for Heart and Lung Transplantation. The registry of the International Society for Heart and Lung Transplantation: fifteenth pediatric heart transplantation report-2012. J Heart Lung Transplant. 2012; 10:1065-72.

2. Singh TP, Almond CS, Piercey G, Gauvreau K. Trends in wait-list mortality in children listed for heart transplantation in the United States: era effect across racial/ethnic groups. Am J Transplant. 2011;12:2692-9.

3. US Food and Drug Administration, US Department of Health and Human Services. Product and Medical Procedures, Recently-Approved Devices: Berlin Heart EXCOR ${ }^{\circledR}$ Pediatric Ventricular Assist Device (VAD)-H100004. Available at: http://www.fda.gov/MedicalDevices/ProductsandMedicalProcedures/ DeviceApprovalsandClearances/Recently-ApprovedDevices/ucm302715.htm. Accessed December 4, 2012

4. Fraser CD Jr, Jaquiss RD, Rosenthal DN, Humpl T, Canter CE, Blackstone EH, et al., Berlin Heart Study Investigators. Prospective trial of a pediatric ventricular assist device. N Engl J Med. 2012;6:532-41.
5. Jeewa A, Manlhiot C, McCrindle BW, Van Arsdell G, Humpl T, Dipchand AI. Outcomes with ventricular assist device versus extracorporeal membrane oxygenation as a bridge to pediatric heart transplantation. Artif Organs. 2010; 12:1087-91.

6. Russo MJ, Hong KN, Davies RR, Chen JM, Sorabella RA, Ascheim DD, et al. Post transplant survival is not diminished in heart transplant recipients bridged with implantable left ventricular assist devices. J Thorac Cardiovasc Surg. 2009;6:1425-32.e1-3.

7. Pal JD, Piacentino V, Cuevas AD, Depp T, Daneshmand MA, Hernandez AF, et al. Impact of left ventricular assist device bridging on post transplan outcomes. Ann Thorac Surg. 2009;5:1457-61.

8. Smedira NG, Hoercher KJ, Yoon DY, Rajeswaran J, Klingman L, Starling RC, et al. Bridge to transplant experience: factors influencing survival to and after cardiac transplant. J Thorac Cardiovasc Surg. 2010;5:1295-305.e1-4.

9. Urban M, Pirk J, Dorazilova Z, Netuka I. How does successful bridging with ventricular assist device affect cardiac transplantation outcome? Interact Cardiovasc Thorac Surg. 2011;4:405-9.

10. Chen JM, Richmond ME, Charette K, Takayama H, Williams M, Gilmore L, et al. A decade of pediatric mechanical circulatory support before and after cardiac transplantation. J Thorac Cardiovasc Surg. 2012;2:344-51.

11. Lin MH, Chou NK, Chen YS, Chi NH, Ko WJ, Yu HY, et al. Outcome in children bridged and nonbridged to cardiac transplantation. Transplant Proc. 2010;3: 916-9.

12. Coskun O, Parsa A, Weitkemper H, Blanz U, Coskun T, Sandica E, et al. Heart transplantation in children after mechanical circulatory support: comparison of heart transplantation with ventricular assist devices and elective heart transplantation. ASAIO J. 2005;5:495-7.

13. Sharma MS, Webber SA, Morell VO, Gandhi SK, Wearden PD, Buchanan JR, et al. Ventricular assist device support in children and adolescents as a bridge to heart transplantation. Ann Thorac Surg. 2006;3:926-32.

14. Varni JW, Seid M, Kurtin PS. PedsQL 4.0: reliability and validity of the Pediatric Quality of Life Inventory version 4.0 generic core scales in healthy and patient populations. Med Care. 2001;8:800-12.

15. Uzark K, Jones K, Burwinkle TM, Varni JW. The Pediatric Quality of Life Inventory ${ }^{\mathrm{TM}}$ in children with heart disease. Prog Pediatric Cardiol. 2003;2: 141-9.

16. Varni JW, Limbers CA, Burwinkle TM. Parent proxy-report of their children's health-related quality of life: an analysis of 13,878 parents' reliability and validity across age subgroups using the PedsQL 4.0 Generic Core Scales. Health Qual Life Outcomes. 2007;5:2.

17. Varni JW, Burwinkle TM, Seid M, Skarr D. The PedsQL 4.0 as a pediatric population health measure: feasibility, reliability, and validity. Ambul Pediatr. 2003;6:329-41.

18. Krieger N, Chen JT, Waterman PD, Soobader MJ, Subramanian SV, Carson R Geocoding and monitoring of US socioeconomic inequalities in mortality and cancer incidence: does the choice of area-based measure and geographic level matter?: the Public Health Disparities Geocoding Project. Am J Epidemiol. 2002;5:471-82. 
19. US Census Bureau; generated by David Ezon; using American Community Survey Summary File Data Retrieval Tool. Available at: http://www.census.gov/acs/ www/data_documentation/summary_file. Accessed September 6, 2012.

20. Uzark K, Jones K, Slusher J, Limbers CA, Burwinkle TM, Varni JW Quality of life in children with heart disease as perceived by children and parents. Pediatrics. 2008:5:e1060-7.

21. Jeewa A, Manlhiot C, McCrindle BW, Van Arsdell G, Humpl T, Dipchand AI. Outcomes with ventricular assist device versus extracorporeal membrane oxygenation as a bridge to pediatric heart transplantation. Artif Organs. 2010; 34:1087-91.
22. Wray J, Lunnon-Wood T, Smith L, Orrells C, Iguchi A, Burch M, et al. Perceived quality of life of children after successful bridging to heart transplantation. $J$ Heart Lung Transplant. 2012;4:381-6.

23. Uzark K, Griffin L, Rodriguez R, Zamberlan M, Murphy P, Nasman C, et al. Quality of life in pediatric heart transplant recipients: a comparison with children with and without heart disease. J Heart Lung Transplant. 2012;6:571-8.

24. Auerbach SR, Richmond ME, Chen JM, Mosca RS, Quaegebeur JM, Addonizio LJ, et al. Multiple risk factors before pediatric cardiac transplantation are associated with increased graft loss. Pediatr Cardiol. 2012; $1: 49-54$. 
APPENDIX TABLE 1. PedsQL Cardiac and Core Module scores stratified by age category

\begin{tabular}{|c|c|c|c|c|c|c|c|c|}
\hline \multirow[b]{2}{*}{ PedsQL section } & \multirow[b]{2}{*}{ Age category (y) } & \multicolumn{2}{|c|}{ Total } & \multicolumn{2}{|c|}{ BTT } & \multicolumn{2}{|c|}{ STT } & \multirow[b]{2}{*}{$P$ value } \\
\hline & & Median & IQR & Median & IQR & Median & IQR & \\
\hline \multicolumn{9}{|l|}{ Core } \\
\hline \multirow{5}{*}{$\begin{array}{l}\text { Psychosocial Health } \\
\text { Summary }\end{array}$} & Total & 83.3 & $69.2-90.8$ & 81.7 & $70.0-90.0$ & 84.2 & $68.3-91.7$ & .66 \\
\hline & & & & & & & & \\
\hline & $2-4$ & 84.8 & $69.2-93.3$ & 84.8 & $64.4-88.6$ & 85 & $76.9-94.2$ & \\
\hline & $5-12$ & 81.7 & $66.7-90$ & 81.7 & $78.3-90$ & 81.67 & $66.7-88.3$ & \\
\hline & $>13$ & 83.3 & $75-90.8$ & 80 & $70-83.3$ & 86.67 & $78.3-91.7$ & \\
\hline \multirow[t]{4}{*}{ Physical Health Summary } & Total & 87.5 & $71.9-100$ & 90.6 & $75-96.9$ & 84.38 & $68.7-100$ & .80 \\
\hline & $2-4$ & 76.6 & $56.2-92.2$ & 75 & $56.2-84.4$ & 100 & $75-100$ & \\
\hline & $5-12$ & 82.8 & $56.2-100$ & 100 & $93.7-100$ & 75 & $56.2-100$ & \\
\hline & $>13$ & 90.6 & 78.1-96.9 & 90.6 & $78.1-96.9$ & 92.19 & $78.1-96.8$ & \\
\hline \multirow[t]{4}{*}{ Total score } & Total & 82.6 & $71-91.3$ & 81.9 & $70.6-92.9$ & 82.61 & $71.7-91.3$ & .53 \\
\hline & $2-4$ & 80.7 & $66.1-94.6$ & 71.4 & $66.1-87.4$ & 80.95 & $80.5-96.4$ & \\
\hline & $5-12$ & 83.1 & $62-89.7$ & 88.0 & $85.9-93.5$ & 80.43 & $62-87.5$ & \\
\hline & $>13$ & 84.8 & $78.3-90.8$ & 80.4 & $78.3-85.9$ & 88.59 & $78.3-91.3$ & \\
\hline \multicolumn{9}{|l|}{ Cardiac } \\
\hline \multirow{4}{*}{$\begin{array}{l}\text { Heart problems and } \\
\text { treatment }\end{array}$} & Total & 89.3 & $85.4-96.4$ & 92.9 & $85.7-100$ & 89.28 & $82.1-96.4$ & .28 \\
\hline & $2-4$ & 92.9 & $87.5-94.6$ & 92.9 & $87.5-94.6$ & 92.86 & $89.3-92.9$ & \\
\hline & $5-12$ & 89.3 & 83.9-96.4 & 96.4 & $89.3-100$ & 85.71 & $83.9-92.9$ & \\
\hline & $>13$ & 89.3 & 80.4-98.2 & 85.7 & $85.7-100$ & 91.07 & $78.6-96.4$ & \\
\hline \multirow[t]{4}{*}{ Treatment II } & Total & 100 & $90-100$ & 95.8 & $83-100$ & 100 & $90-100$ & .33 \\
\hline & $2-4$ & 95.8 & $83.3-100$ & 83.3 & $79.2-100$ & 100 & $91.7-100$ & \\
\hline & $5-12$ & 100 & $91.7-100$ & 100 & $100-100$ & 100 & $90.8-100$ & \\
\hline & $>13$ & 95 & $87.5-100$ & 90 & $80-100$ & 95 & $90-100$ & \\
\hline \multirow{4}{*}{$\begin{array}{l}\text { Perceived physical } \\
\text { appearance }\end{array}$} & Total & 100 & $83.3-100$ & 100 & $83.3-100$ & 100 & $83.3-100$ & .54 \\
\hline & $2-4$ & 100 & $100-100$ & 100 & $95.8-100$ & 100 & $100-100$ & \\
\hline & $5-12$ & 100 & $83.3-100$ & 100 & $83.3-100$ & 100 & $87.5-100$ & \\
\hline & $>13$ & 83.3 & $66.7-100$ & 100 & $83.3-100$ & 83.33 & $66.7-100$ & \\
\hline \multirow[t]{4}{*}{ Treatment anxiety } & Total & 100 & $75-100$ & 87.5 & $62.5-100$ & 100 & $81.2-100$ & .43 \\
\hline & $2-4$ & 81.2 & $65.6-100$ & 75 & $31.2-87$ & 93.75 & $87.5-100$ & \\
\hline & $5-12$ & 93.7 & $78.1-100$ & 87.5 & $87.5-100$ & 93.75 & $78.1-100$ & \\
\hline & $>13$ & 100 & $84.4-100$ & 100 & $81.2-100$ & 100 & $87.5-100$ & \\
\hline \multirow[t]{4}{*}{ Cognitive problems } & Total & 80 & $50-95$ & 80 & $50-95$ & 77.5 & $55-95$ & .58 \\
\hline & $2-4$ & 70.8 & $50-95.8$ & 50 & $50-87.5$ & 75 & $66.7-100$ & \\
\hline & $5-12$ & 65 & $50-92.5$ & 50 & $40-60$ & 75 & $50-95$ & \\
\hline & $>13$ & 85 & $70-97.5$ & 95 & $80-100$ & 80 & $100-100$ & \\
\hline \multirow[t]{4}{*}{ Communication } & Total & 100 & $75-100$ & 100 & $66.7-100$ & 100 & $83.3-100$ & .28 \\
\hline & $2-4$ & 45.8 & $0-100$ & 25 & $0-91$ & 66.67 & $0-100$ & \\
\hline & $5-12$ & 100 & $66.7-100$ & 100 & $66.7-100$ & 100 & $75-100$ & \\
\hline & $>13$ & 100 & $100-100$ & 100 & $100-100$ & 100 & $100-100$ & \\
\hline
\end{tabular}

Peds $Q L$, Pediatric Quality of Life Inventory; $B T T$, bridge to transplantation; $S T T$, straight to transplantation; $I Q R$, interquartile range (25th-75th percentiles). 
APPENDIX TABLE 2. Clinical factors affecting outcome of patients BTT with VAD

Ventilator use on day Hemodialysis use on day before TPN use on day

\begin{tabular}{|c|c|c|c|c|c|c|c|c|c|c|c|c|c|c|c|c|c|}
\hline \multirow[b]{2}{*}{ dsQL section } & \multicolumn{3}{|c|}{$\begin{array}{l}\text { Ventilator use on day } \\
\text { before VAD implantation }\end{array}$} & \multicolumn{3}{|c|}{$\begin{array}{l}\text { Hemodialysis use on day before } \\
\text { VAD implantation }\end{array}$} & \multicolumn{3}{|c|}{$\begin{array}{l}\text { TPN use on day } \\
\text { before VAD implantation }\end{array}$} & \multicolumn{3}{|c|}{ Pump change } & \multicolumn{4}{|c|}{ ce } & $\begin{array}{c}\text { Parent } \\
\text { education level }\end{array}$ \\
\hline & $\begin{array}{c}\text { Yes } \\
(\mathrm{n}=12)\end{array}$ & $\begin{array}{c}\text { No } \\
(\mathbf{n}=9)\end{array}$ & $\begin{array}{c}P \\
\text { value }\end{array}$ & $\begin{array}{c}\text { Yes } \\
(\mathbf{n}=\mathbf{2})\end{array}$ & $\begin{array}{c}\text { No } \\
(\mathrm{n}=19)\end{array}$ & $\begin{array}{c}P \\
\text { value }\end{array}$ & $\begin{array}{c}\text { Yes } \\
(\mathbf{n}=12)\end{array}$ & No $(\mathbf{n}=9)$ & $\begin{array}{c}P \\
\text { value }\end{array}$ & $\begin{array}{c}\text { Yes } \\
(\mathbf{n}=\mathbf{1 0})\end{array}$ & No $(\mathbf{n}=\mathbf{3})$ & $\begin{array}{c}P \\
\text { value }\end{array}$ & $\begin{array}{c}\text { Black } \\
(\mathrm{n}=7)\end{array}$ & $\begin{array}{l}\text { Hispanic } \\
(\mathbf{n}=\mathbf{1 0})\end{array}$ & $\begin{array}{l}\text { White } \\
(\mathbf{n}=4)\end{array}$ & $\begin{array}{c}P \\
\text { value }\end{array}$ & $\begin{array}{l}\text { HS incomplete HS complete Some college or } \\
\text { or less }(\mathrm{n}=4) \quad(\mathrm{n}=5)\end{array}$ \\
\hline
\end{tabular}

Core

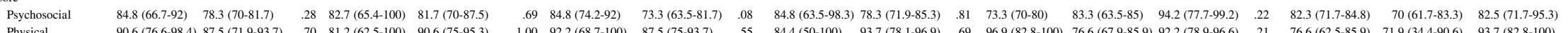

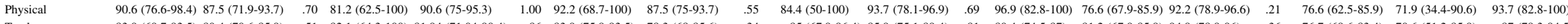

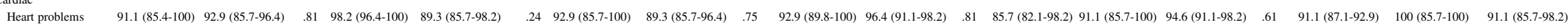

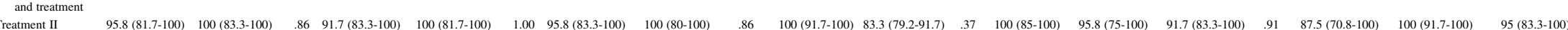

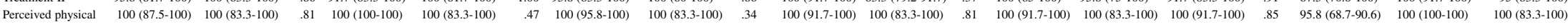

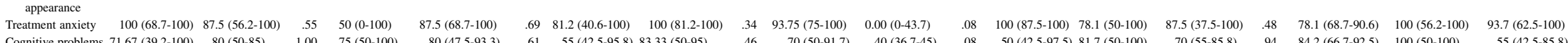

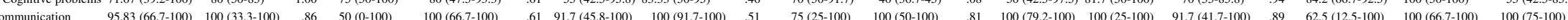

Data reported as median and interquartile range (25th-75th percentile). $B T T$, Bridge to transplantation; VAD, ventricular assist device; Peds $Q L$, Pediatric Quality of Life Inventory; $T P N$, total parenteral nutrition; $H S$, high school; $C P B$, cardiopulmonary bypass; $S E S$, socioeconomic status; $C C$, correlation coefficient. 
